\title{
RESEÑAS
}

\section{El Brexit: la relación del Reino Unido con la Unión Europea}

\author{
Carlos García Fernández \\ Facultad de Estudios Globales, Universidad Anáhuac México, México
}

https://doi.org/10.36105/iut.2021n33.13

\begin{abstract}
Alicia Gutiérrez González, El Brexit: la relación del Reino Unido con la Unión Europea, México, Tirant Lo Blanch, Universidad Anáhuac México, 2020, p. 136, ISBN 978-84-1355-711-3.
\end{abstract}

El libro de la doctora Alicia Gutiérrez González es muy valioso debido al análisis histórico-jurídico que hace de la relación que tuvo el Reino Unido con la Unión Europea, (UE) durante 47 años, como parte del club comunitario. Aunque existen diversos libros y ensayos que tratan el tema, no lo hacen desde la perspectiva jurídico-internacional sino, exclusivamente, desde la óptica periodística, histórica o política. Sin embargo, la contribución de esta obra yace en que, desde la señalada perspectiva, aborda el análisis de las sentencias emanadas del Tribunal de Justicia de la Unión Europea, de las sentencias dictadas por la Corte Suprema del Reino Unido y de todos los procedimientos que se tuvieron que llevar a cabo para la retirada del Reino Unido de dicha Unión. La obra indica, de manera exacta, los tiempos del proceso de retirada establecidos en el ordenamiento jurídico comunitario, así como los rechazos al acuerdo de retirada entre esta última y el gobierno británico, las prórrogas solicitadas, las mociones de desconfianza y el período transitorio. Esto hace que el libro aporte al lector el andamiaje histórico y legal para comprender el proceso, los tiempos, las disputas y las dificultades que conllevó la aceptación del señalado cuerdo de retirada.

La obra está escrita de manera accesible para entender la relación que tuvo el Reino Unido con la Unión Europea. No se necesitan conocimientos previos debido a que, conforme se van leyendo los capítulos, es posible ir concatenando los eventos, por lo que, así, se llega a una conclusión preliminar que da la pauta 
para el siguiente capítulo, hasta llegar al final del libro. La autora explica las causas por las que el Reino Unido decidió retirarse de la Unión Europea después de 47 años y apunta que una de las razones principales estriba en que el Reino Unido nunca estuvo comprometido, en lo fundamental, con el proyecto de integración de la Unión Europea, y que lo único que buscaba era el éxito económico manteniendo, por décadas, una "Europa a la carta", donde elegía en qué rubros quería participar y en qué no, bajo el derecho de reserva estipulado en los propios tratados constitutivos.

Este libro, de 136 páginas, se divide en seis capítulos cortos que incluyen tablas, gráficas, fechas, datos, artículos invocados, sentencias, etc., lo que hace que su lectura resulte atractiva y ligera, pero honda al mismo tiempo. En la obra se pueden apreciar los momentos más cruciales del divorcio británico del club comunitario.

La Dra. Gutiérrez logra llevar de la mano al lector por un recorrido, desde la posguerra hasta la salida del Reino Unido de la Unión Europea, el 31 de diciembre de 2020, una vez fenecido el periodo transitorio. Aunque el libro se publicó antes de que se lograra un acuerdo comercial entre las dos instancias políticas, la autora logra visualizar los posibles desafíos que tendría el Reino Unido en un futuro inmediato e, incluso, anticipa los posibles escenarios con vistas a la concertación de un Acuerdo de Libre Comercio entre ambas partes.

La obra inicia con un capítulo que abarca la Europa de la posguerra y la reactivación económica mediante el Plan Marshall, destacándose la importancia que le confiere Europa a la protección los derechos humanos, así como al mantenimiento de la paz y la seguridad internacionales, después de la Segunda Guerra Mundial. La autora logra transportar al lector a aquellos tiempos donde los problemas y las necesidades de la época unieron a los países con el ferviente deseo de una paz duradera acompañada de crecimiento económico. Se trae a colación, en ese tenor, el discurso del entonces primer ministro británico Winston Churchill de crear unos Estados Unidos de Europa, pero sin el Reino Unido, lo que, en opinión de la autora, ponía ya en evidencia esa falta de compromiso británico con el proyecto comunitario trazado por Jean Monnet, Konrad Adenauer, Alcide De Gasperi y Robert Schuman, entre otros. También, se menciona el Plan Schuman y la creación de la Comunidad Europea del Carbón y del Acero (CECA), como el inicio de la integración de lo que, años después, será la Unión Europea, en aras de edificar el proyecto comunitario sobre la base de los principios de igualdad, solidaridad y subsidiariedad entre los primeros países fundadores (Alemania, Bélgica, Francia, Italia, Luxemburgo y los Países Bajos). No obstante, la pretendida integración no estaba exenta de retos y dificultades: a manera de ejemplo, la autora muestra cómo Alemania, al encontrarse devastada por la guerra y sin mano de obra calificada para realizar trabajo pesado en los sectores minero y automotor, entre otros, decide ofertar puestos de trabajo para que se pudieran cumplir esas funciones, denominando a tales personas como "trabajadores invitados" (Gastarbeiter), evitando así denominarlos "extranjeros", lo que podría ser políticamente incorrecto y generar algún tipo de efecto desafortunado. Este ejemplo que aporta 
la Dra. Gutiérrez revela cómo, también en aquellos tiempos, las personas se veían obligadas a migrar por cuestiones de trabajo y, desde luego, cómo la integración de los inmigrantes, en los países de destino, ha sido complicada.

El capítulo segundo muestra, claramente, la negativa del Reino Unido a integrarse, del todo, en la UE. La autora comenta que, en 1975 y a sólo dos años de haberse adherido a las entonces denominadas "Comunidades Europeas", aquél solicitó un referéndum para su permanencia o salida del mercado común. En esa campaña, tanto los conservadores (tories) como los laboristas apoyaron la permanencia, situación que no sucedió en el referéndum de 2016, donde ganó la salida de la Unión Europea con un 51.9\%, debido al discurso antiinmigrante y a las noticias falsas que provenían de la campaña de Boris Johnson (actual primer ministro) y Nigel Farage. Como lo menciona la autora, el Reino Unido tuvo una "Europa a la carta", que lo excluía de participar y comprometerse en varios rubros medulares como la Eurozona o el Espacio Schengen y, pese a eso, decidió retirarse de la Unión Europea sin tomar en cuenta todo lo que se había logrado a lo largo de décadas de progresiva integración con sus socios comunitarios.

Los capítulos tercero y cuarto abordan, respectivamente, tanto el proceso jurídico del Brexit como los desafíos del primer acuerdo de retirada celebrado por la entonces primera ministra Theresa May. La autora explica, de manera clara y precisa, los tres rechazos que tuvo este acuerdo de retirada en el Parlamento del Reino Unido (tanto en la Cámara de los Comunes como en la Cámara de los Lores); las dos mociones de desconfianza por las que tuvo que pasar Theresa May, así como las dos prórrogas que se tuvieron que solicitar al Consejo Europeo para lograr que el Reino Unido no saliera de la Unión Europea sin un acuerdo y, así, evitar el Brexit duro al que muchos le temían.

Por su parte, el capítulo quinto menciona las elecciones al Parlamento Europeo del 23 al 26 de mayo de 2019, así como la elección del nuevo primer ministro del Reino Unido, Boris Johnson, tras la dimisión de Theresa May. Esta parte de la obra es medular para entender el Brexit, ya que los discursos de Boris Johnson y de Nigel Farage (de cara al referéndum del 23 de junio de 2016) lograron conectar con el electorado de ultraderecha (en las tablas del capítulo se aprecia, claramente, el ascenso de dichos grupos, tanto en los escaños del Parlamento Europeo como en los partidos del Reino Unido) y con aquellos británicos que anhelaban los tiempos pasados (sobre todo, en las áreas rurales). El lema de sus campañas: "recuperar el control", les funcionó. Otro acontecimiento relevante que se destaca concierne a la suspensión del Parlamento del Reino Unido, del 10 de septiembre a 14 de octubre del 2019, misma que resultó muy controvertida, ya que lo que se quería lograr era callar la voz de los parlamentarios, situación que no se logró del todo gracias a la sentencia de la Corte Suprema del Reino Unido.

El sexto y último capítulo trata sobre el acuerdo de retirada y las elecciones del 12 de diciembre de 2019 para la nueva composición de la Cámara de los Comunes. Se precisan, además, tres temas pendientes de enorme relevancia: la posible reunificación de Irlanda del Norte, el referéndum de independencia de Escocia y la situación del Peñón de Gibraltar. 
En el balance, la obra de la Dra. Alicia Gutiérrez precisa lo difícil que resulta, para un Estado miembro, retirarse de la Unión Europea, no sólo por lo referente a las implicaciones jurídicas y políticas, sino porque el proceso es largo y existen tiempos perentorios que cumplir. La retirada de la Unión Europea le costó al Reino Unido, por lo pronto, tres prórrogas, dos primeros ministros (ya que David Cameron dimitió tras el triunfo del Brexit, el 23 de junio de 2016, y Theresa May hizo lo propio después de dos mociones de desconfianza) y un periodo transitorio.

En mi opinión, el libro logra su cometido, ya que siembra la inquietud de querer saber más acerca del Brexit, de la futura relación que tendrán los británicos con la Unión Europea, y la que ésta, a su vez, tendrá con Escocia, la República de Irlanda y el Peñón de Gibraltar.

Esta obra está bajo licencia internacional Creative Commons ReconocimientoNo-Comercial-CompartirIgual 4.0.

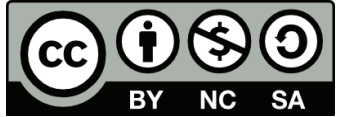

